\title{
Missed Nursing Care in Intensive Care Patients Subjected to Interhospital Capacity Transfers: A Retrospective Matched Case-Control Chart Review
}

Jonas Karlsson ( $\sim$ jonas.karlsson@hb.se )

University of Borås: Hogskolan i Boras https://orcid.org/0000-0002-4844-5266

Isabell Fridh

University of Borås: Hogskolan i Boras

Kristina Schildmeijer

Linnaeus University: Linneuniversitet

Magnus Andersson Hagiwara

University of Borås: Hogskolan i Boras

\section{Research}

Keywords: Capacity transfers, Intensive care, Intensive care unit, Missed nursing care, Patient transfer, Transportation of patients

Posted Date: June 29th, 2021

DOI: https://doi.org/10.21203/rs.3.rs-652662/v1

License: (c) (i) This work is licensed under a Creative Commons Attribution 4.0 International License. Read Full License 


\section{Title}

Missed nursing care in intensive care patients subjected to interhospital capacity transfers: a retrospective matched case-control chart review

\section{Authors}

Jonas Karlsson $^{1 *}$, Isabell Fridh ${ }^{1,2}$, Kristina Schildmeijer ${ }^{3}$, Magnus Andersson Hagiwara ${ }^{4}$

${ }^{1}$ Faculty of Caring Science, Work Life and Social Welfare, University of Borås, 50190 Borås, Sweden

${ }^{2}$ Department of Anesthesiology and Intensive Care, Sahlgrenska University Hospital, Blå Stråket 5, 41345 Gothenburg, Sweden

${ }^{3}$ Faculty of Health and Life Sciences, Linnaeus University, 39182 Kalmar, Sweden

${ }^{4}$ Faculty of Caring Science, Work Life and Social Welfare, Centre for Prehospital Research, University of Borås, 50190 Borås, Sweden

\section{*Corresponding author:}

Jonas Karlsson, Faculty of Caring Science, Work Life and Social Welfare, University of Borås, Allégatan 1, 50190 Borås, Sweden. Tel.: +46701440035

Email address: Jonas.karlsson@hb.se

ORCID iD: https://orcid.org/0000-0002-4844-5266 


\begin{abstract}

\section{Background}

The number of patients undergoing an interhospital intensive care unit-to-unit capacity transfer has dramatically increased. These transfers are complex, pose a risk for the patients and have been linked to increased intensive care unit length of stay and mortality, but the reasons for this are not known. We hypothesised that there was a difference in the incidence of missed nursing care among patients subjected to capacity transfer compared with patients not subjected to any transfer during their intensive care stay.
\end{abstract}

\title{
Methods
}

A retrospective case-control chart review was conducted on adult patients who between January 1, 2009, and January 31, 2020, underwent an interhospital intensive care unit-to-unit capacity transfer. We applied a matched control group by 1:2 matching. Missed nursing care was based on four variables: mobilisation, tooth brushing, oral care and nutrition. Data were retrieved from the local database and the patient's medical charts at two general level 3 ICUs.

\section{Results}

The case group $(\mathrm{n}=63)$ received significantly less mobilisation $(p<0.05)$, mean $5.94(2.36)$, compared with the control group $(\mathrm{n}=126)$, mean $7.74(2.96)$. In a subanalysis of the patients treated with invasive positive pressure ventilation and noninvasive positive pressure ventilation, the case group $(\mathrm{n}=56)$ was found to receive significantly less oral care $(p<0.05)$, median 3.50 $(1.00-6.00)$, compared with the control group $(n=80)$, median $5.00(2.00-7.75)$. None of the other variables were significantly related to interhospital intensive care unit-to-unit capacity transfers.

\section{Conclusion}

In critically ill patients, interhospital intensive care unit-to-unit capacity transfers were associated with missed nursing care. Future studies, focusing on capacity transfers should 
consider missed nursing care when the causes of increased intensive care unit length of stay and mortality are to be investigated.

\section{Key words}

Capacity transfers, Intensive care, Intensive care unit, Missed nursing care, Patient transfer, Transportation of patients 


\section{Background}

Over the past decade in Sweden, the number of patients undergoing interhospital intensive care unit-to-unit transfers because of a lack of intensive care resources (capacity transfers), such as beds or health personnel, has increased more than threefold (1), and a similar trend has also been seen internationally $(2,3)$. In situations with a lack of intensive care unit (ICU) capacity, a selection process is carried out with the aim of selecting the patient who is the most stable and suitable for a transfer and who is not expected to be adversely affected by a transfer and care at another ICU. Previous research $(4,5)$ has shown the tendency for interhospital intensive care unit-to-unit capacity transfers may be associated with an increased length of intensive care and hospital stay. In general, interhospital intensive care unit-to-unit transfers are also associated with adverse events that may affect patient safety (6-9). Regarding mortality, the state of knowledge is more unclear, without a clear consensus $(4,5,10,11)$. Transfers are complex and require clinical skill and efficiency, as well as well-functioning interprofessional collaboration and communication $(2,6,12)$. However, when a decision to transfer a patient is made, there is a risk that the essential nursing activities important for critically ill patients are being missed while focusing solely on the transfer. Proper communication and teamwork have previously been considered important factors in reducing the incidence of missed nursing care (MNC) (1316). MNC is known to adversely affect patients' clinical outcomes, such as causing adverse events, 30-day hospital readmission and mortality (16-19). Research focusing on MNC within an intensive care context - especially in relation to intensive care unit-to-unit transfers-is sparsely illuminated $(16,19,20)$. Therefore, in the current study, we adopted the hypothesis that there was a difference in the incidence of MNC among patients who underwent an interhospital intensive care unit-to-unit capacity transfer compared with patients who did not undergo any interhospital intensive care unit-to-unit transfer during their intensive care stay. 


\section{Methods}

\section{Study design}

The current study was based on a retrospective case-control chart review of patients subjected to an interhospital intensive care unit-to-unit capacity transfer. The manuscript was conducted in accordance with the Strengthening the Reporting of Observational Studies in Epidemiology (STROBE) statement: Guidelines for Reporting Observational Studies (21).

\section{Setting}

The study was conducted in two general level $3(22,23)$ ICUs (primary and secondary ICU) in Sweden that were located within the same region and that contained six and seven beds, respectively. The hospitals served a population of almost 325,000 people. Depending on the burden of care in the ICUs, the critical care registered nurse (CCRN) was generally assisted by one or two assistant nurses. Transfers were carried out according to existing guidelines and recommendations, but no dedicated transfer teams existed (24). The ambulances allowed for the necessary equipment for ongoing full intensive care. A CCRN or certified registered nurse anaesthetist (CRNA) was responsible for the patient's care, and in special circumstances, an ICU physician accompanied the nurse.

\section{Definition and characteristics of the cases and controls}

We used the hospital's local ICU register to identify the cases and controls and extract validated data that were sent to the Swedish Intensive Care Registry (SIR). Inclusion criteria were adult patients admitted to the primary ICU between January 1, 2009, and January 31, 2020, who, because of lack of ICU resources, underwent a capacity transfer to the secondary ICU. The exclusion criteria were being transferred to another ICU than the secondary ICU; an arrival route to the primary ICU by interhospital transfer from an ICU or a ward at another hospital; 
having an ICU stay at the primary or secondary ICU for less than 15 hours; and missing or incomplete medical records preventing chart review. The time period was defined by the introduction of 'transfer to another ICU due to lack of resource' as a SIR national quality indicator in the ICUs. The inclusion and exclusion criteria used to determine the case group are shown in Fig. 1. 
Fulfilling the inclusion criteria; adult patients admitted to the primary ICU between January 1, 2009, and January 31, 2020, who because of lack of ICU resources, underwent a capacity transfer to the secondary ICU $(n=106)$.

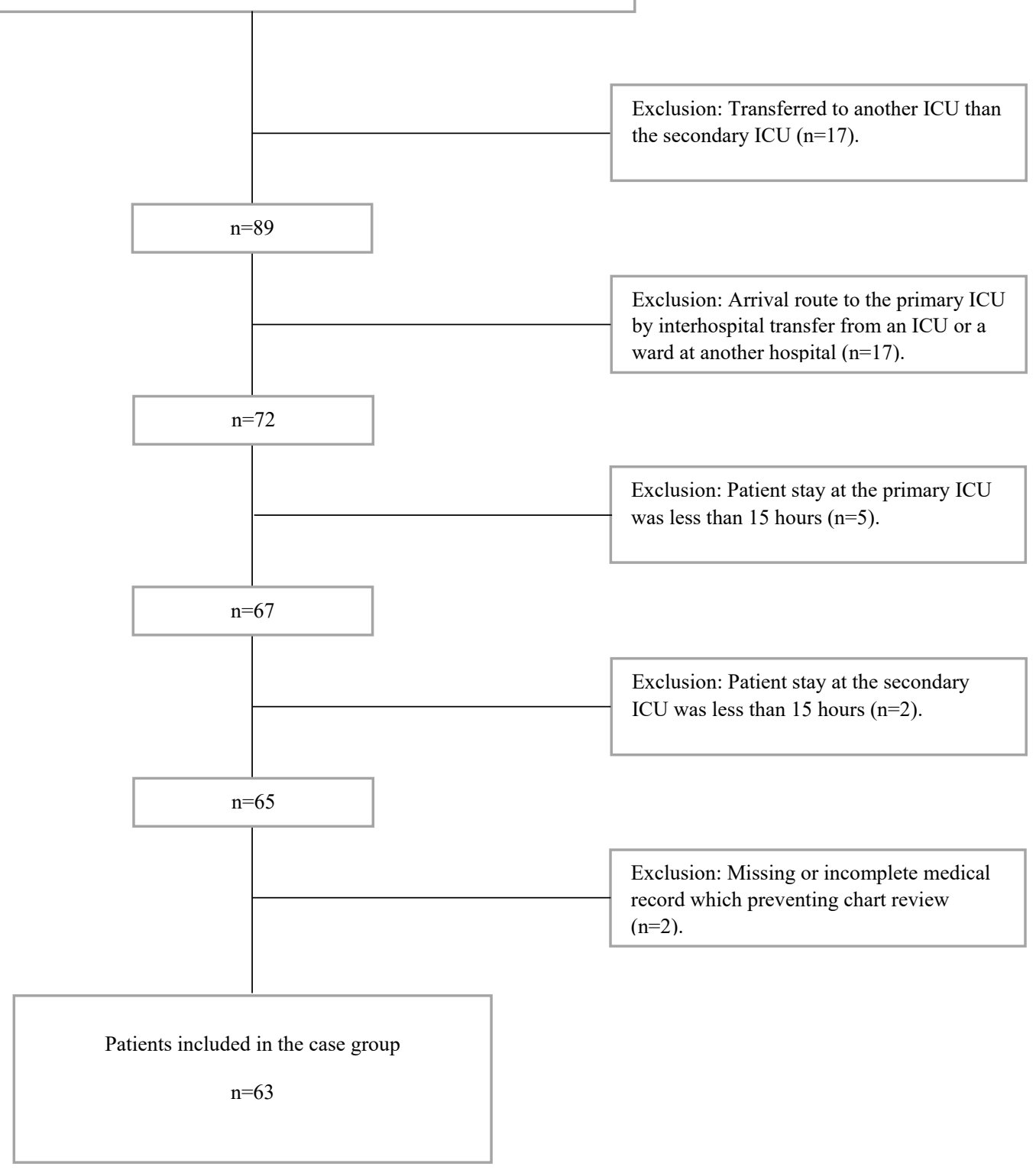

Fig. 1 Flowchart representing the inclusion and exclusion process

Second, the patients in the control group were selected based on patients at the primary ICU who did not undergo any form of interhospital intensive care unit-to-unit transfer during their intensive care stay. Here, we applied a matched control group by matching two controls to each patient in the case group (1:2 matching). We initiated the matching by selecting patients who had an ICU stay within the same year as the case patient. Then, matching was based on a 
hierarchy of criteria for the best possible match to age, sex, clinical affiliation, simplified acute physiology score (SAPS), estimated mortality risk (EMR), total burden of care per hour and day during the intensive care stay and nine equivalents of nursing manpower use score (NEMS) per day (Table 1) (25-28).

\section{Missed nursing care — definition of measured variables}

MNC was based on four variables: mobilisation, tooth brushing, oral care and nutrition, which were collected from the patient's medical chart. All variables were considered significant for the care of critically ill patients (29-32). According to the ICUs' guidelines, all these variables must be routinely documented in the patient's medical chart. Mobilisation included all forms of documented activities in the form of changes in position, sitting on a bed or in an armchair, bed cycling, standing with walking aids and exercise with a physiotherapist. According to ICU guidelines, tooth brushing should be performed twice a day. Based on the time period for the chart review, we determined the maximum number of tooth brushings the patient could receive. Oral care includes mouth moisturiser to lips and mucous membranes with a saliva substitute or moistening gel with or without oral chlorhexidine. The variable nutrition was examined based on the patient's prescribed number of kilocalories (kcal) for the day of transfer in relation to the documented number of kcal the patient actually received.

\section{Data collection}

First, with the aim of ensuring optimal data collection, we designed a data collection tool (33, 34) [see Additional file 1]; we defined the time period for the chart review based on the time (nearest full hour) when the case patient left the primary ICU and arrived at the secondary ICU, respectively. Based on these times, the medical chart was reviewed 15 hours backwards (primary ICU) and 15 hours forwards (secondary ICU) in time, totalling 30 hours of review. 
Next, based on the best possible match for the measured total burden of care during each case and control patient's ICU stay in the primary ICU, we determined the time period for the chart review for each matched control patient. Thereafter, we systematically conducted the chart review in accordance with the data collection tool [see Additional file 1].

\section{Statistical analysis}

Descriptive data are presented as the mean (SD), median (IQR), ratio and number. Closeness of matching is also presented as percentage. Data were checked for normality, and equality of variances (homogeneity of variance) were verified with a parametric or nonparametric Levene's test (35-37). Based on either a normal or nonnormal distribution, closeness of matching across the case and control groups and variables for MNC were tested with Mann-Whitney U-tests, Chi-Square tests or Independent samples t-tests, as appropriate. We used IBM SPSS Statistics version 27.0 for data analyses. A $p$-value $<0.05$ was considered significant in all comparisons between groups.

\section{Results}

\section{Case and control group characteristics}

The median ages of the case and control groups were 73 (65-80) and 72 (65-79), respectively, and within the total cohort, most patients were men. Most of the patients in both the groups had a medical affiliation, followed by surgical, orthopaedic and urological affiliations. Matching was successful in the form of an equal distribution across the case and control groups for age, sex, clinical affiliation, SAPS and EMR. For matching criterion concerning the burden of care, in the form of total burden of care per hour or day and NEMS per day during the ICU stay, no equal distribution across the case and control group was achieved. For all of these criteria, the case group showed a higher burden of care compared with the control group (Table 1). 
Table 1. Description of the case and control group characteristics and closeness of matching. Presented as mean (SD), median (IQR), ratio, $p$-values and percentage matching between the groups.

\begin{tabular}{|c|c|c|c|c|}
\hline $\begin{array}{l}\text { Matching } \\
\text { criterion }\end{array}$ & $\begin{array}{l}\text { Case group } \\
\mathrm{N}=63\end{array}$ & $\begin{array}{l}\text { Control } \\
\text { group } \\
\mathrm{N}=126\end{array}$ & $\begin{array}{l}p \text { for equal distribution } \\
\text { of criterion across case- } \\
\text { and control group }\end{array}$ & $\begin{array}{l}\text { Percentage } \\
\text { matching } \\
\text { between } \\
\text { groups } \\
\end{array}$ \\
\hline \multicolumn{5}{|l|}{ Age $( \pm 5$ year } \\
\hline Mdn (IQR) & $73(65-80)$ & $72(65-79)$ & $p=0.767^{1}$ & $99 \%$ \\
\hline $\begin{array}{l}\text { Sex ratio } \\
\text { (Male/Female) }\end{array}$ & $41: 22$ & $82: 44$ & $p=1.000^{2}$ & $100 \%$ \\
\hline \multicolumn{5}{|l|}{$\begin{array}{l}\text { Clinical } \\
\text { affiliation }\end{array}$} \\
\hline Medical & 52 & 104 & $p=1.000^{2}$ & $100 \%$ \\
\hline Surgical & 7 & 14 & & \\
\hline Orthopaedic & 2 & 4 & & \\
\hline Urological & 2 & 4 & & \\
\hline \multicolumn{5}{|l|}{ SAPS } \\
\hline Mean (SD) & $63.35(12.33)$ & $65.33(14.92)$ & $p=0.364^{3}$ & $97 \%$ \\
\hline \multicolumn{5}{|l|}{ EMR } \\
\hline Mdn (IQR) & $\begin{array}{l}26.10(13.50- \\
36.00)\end{array}$ & $\begin{array}{l}26.10 \\
(12.20- \\
50.90)\end{array}$ & $p=0.431^{1}$ & $85 \%$ \\
\hline \multicolumn{5}{|l|}{$\begin{array}{l}\text { Total burden of } \\
\text { care per hour } \\
\text { during the ICU } \\
\text { stay }\end{array}$} \\
\hline Mdn (IQR) & $2.34(2.19-2.67)$ & $\begin{array}{l}2.19(2.05- \\
2.29)\end{array}$ & $p<0.05^{1}$ & $88 \%$ \\
\hline \multicolumn{5}{|l|}{$\begin{array}{l}\text { Total burden of } \\
\text { care per day } \\
\text { during the ICU } \\
\text { stay }\end{array}$} \\
\hline Mdn (IQR) & $\begin{array}{l}42.30(36.50- \\
48.50)\end{array}$ & $\begin{array}{l}40.15 \\
(34.27- \\
45.25)\end{array}$ & $p<0.05^{1}$ & $94 \%$ \\
\hline \multicolumn{5}{|l|}{$\begin{array}{l}\text { NEMS per day } \\
\text { during the ICU } \\
\text { stay }\end{array}$} \\
\hline Mdn (IQR) & $\begin{array}{l}32.00(29.00- \\
34.00)\end{array}$ & $\begin{array}{l}26.00 \\
(23.00- \\
28.70)\end{array}$ & $p<0.05^{1}$ & $83 \%$ \\
\hline
\end{tabular}

${ }^{1}$ Mann-Whitney U test

${ }^{2}$ Chi-Square test

${ }^{3}$ Independent samples t-test

SAPS - Simplified Acute Physiology Score

EMR - Estimated Mortality Risk

NEMS - Nine Equivalents of nursing Manpower use Score 


\section{Comparison of missed nursing care}

Table 2 displays an overview of the comparison of the MNC variables between the case and control groups. By comparison, the case group $(n=63)$ received significantly less mobilisation, with a mean of 5.94 (2.36) compared with the control group $(n=126)$, which had a mean of 7.74 (2.96). However, we found no significant difference between the cases and controls regarding the amount of tooth brushing received and oral care. For the MNC variables tooth brushing and oral care, we chose to perform a subanalysis based only on the patients treated with invasive positive pressure ventilation (IPPV) and noninvasive positive pressure ventilation (NIPPV). Here, the case group $(n=56)$ was found to receive significantly less oral care, with a median $3.50(1.00-6.00)$, compared with the control group $(n=80)$, which had a median 5.00 (2.00-7.75); however, tooth brushings remained as having no significant differences. Finally, we aimed at comparing the differences between the prescribed number of kcal and number of kcal received. After excluding the cases and controls where it was not possible to perform a comparison because of a lack of documentation in the medical charts, $\mathrm{n}=35$ remained in both the case and control groups. This meant missing data to the extent of $72.2 \%$ for the control group and $44.4 \%$ for the case group. Although the case group appeared to be affected by a larger difference in the prescribed and received number of kcal, with a median of $391.00(135.00$ 928.00) versus a median of 200.00 (70.00-684.00), this difference was not significant. 
Table 2. Comparison of MNC variables between the case- and control groups. Presented as mean (SD), median (IQR) and $p$-values.

\begin{tabular}{|c|c|c|c|}
\hline $\begin{array}{l}\text { Missed nursing care } \\
\text { variables }\end{array}$ & $\begin{array}{l}\text { Case group } \\
\mathrm{N}=63\end{array}$ & $\begin{array}{l}\text { Control group } \\
\mathrm{N}=126 \\
\end{array}$ & $p$ \\
\hline \multicolumn{4}{|l|}{ Mobilisation } \\
\hline $\mathrm{N}$ & 63 & 126 & \\
\hline Mean (SD) & $5.94(2.36)$ & $7.74(2.96)$ & $<0.05^{1}$ \\
\hline \multicolumn{4}{|l|}{ Tooth brushings } \\
\hline $\mathrm{N}$ & 63 & 126 & \\
\hline Mdn (IQR) & $2.00(1.00-2.00)$ & $2.00(1.00-2.00)$ & $0.322^{2}$ \\
\hline \multicolumn{4}{|l|}{$\begin{array}{l}\text { Tooth brushings } \\
\text { (subanalysis) }\end{array}$} \\
\hline $\mathrm{N}$ & 56 & 80 & \\
\hline Mdn (IQR) & $3.00(1.00-6.00)$ & $3.00(0.00-6.25)$ & $0.124^{2}$ \\
\hline \multicolumn{4}{|l|}{ Oral care } \\
\hline $\mathrm{N}$ & 63 & 126 & \\
\hline Mdn (IQR) & $3.00(1.00-6.00)$ & $3.00(0.00-6.25)$ & $0.578^{2}$ \\
\hline \multicolumn{4}{|l|}{$\begin{array}{l}\text { Oral care } \\
\text { (subanalysis) }\end{array}$} \\
\hline $\mathrm{N}$ & 56 & 80 & \\
\hline Mdn (IQR) & $3.50(1.00-6.00)$ & $5.00(2.00-7.75)$ & $<0.05^{2}$ \\
\hline \multicolumn{4}{|l|}{$\begin{array}{l}\text { Difference between } \\
\text { prescribed and } \\
\text { given kcal }\end{array}$} \\
\hline $\mathrm{N}$ & 35 & 35 & \\
\hline Mdn (IQR) & $391.00(135.00-928.00)$ & $200.00(70.00-684.00)$ & $0.077^{2}$ \\
\hline
\end{tabular}

\section{Discussion}

The main finding of the present study was that critically ill patients undergoing interhospital intensive care unit-to-unit capacity transfer between two level 3 ICUs were affected by MNC in the form of less mobilisation and less oral care compared with a matched control group that did not undergo any interhospital intensive care unit-to-unit transfer during their intensive care stay. Although there have been studies $(4,5,10,11)$ focusing on the relationship between interhospital intensive care unit-to-unit transfers and mortality and ICU length of stay, to the best of our knowledge, this is the first study focusing on the possible relationships between transfers and MNC. MNC can adversely affect patient outcomes (16). With today's centralisation of specialised intensive care in combination with the fact that Sweden has among 
Europe's lowest number of available ICU beds $(38,39)$, the effect of interhospital intensive care unit-to-unit capacity transfers on MNC is an important issue. Physiotherapy together with early active mobilisation have been some of the strategies to prevent the negative effects of critical illness, such as functional consequences, postintensive care syndrome and ICU-acquired weakness $(40,41)$. Delayed mobilisation has previously been linked to longer ICU and hospital lengths of stay $(42,43)$. Therefore, $\mathrm{MNC}$ in the form of less mobilisation that may occur during transfers could also be a contributing factor to longer ICU and hospital length of stay, as previously noted among transferred patients $(4,5)$. At the same time, one must be humble to the fact that more research is needed to fully understand the effects of mobilisation on critically ill patients $(40,44)$. One reason for the lack of significant differences for tooth brushing and oral care in the first analysis may be that there were significantly more patients in the control group, $n=7$ for the case group and $n=46$ for the control group, who were not treated with any form of positive pressure ventilation. We assume that there is more of a focus on tooth brushings and oral care when patients are treated with NIPPV or IPPV. Regardless, in a subanalysis, our study shows that patients who are transferred receive less oral care. Oral care reduces the incidence of developing ventilator-associated pneumonia (VAP) in critically ill patients, which is a potentially serious complication that can affect patients who have received mechanical ventilation (32). In addition, oral care is a basic hygiene requirement and essential component of the care for critically ill patients, which provides comfort and enhances their sense of wellbeing $(45,46)$. Although documentation regarding nutrition was lacking, it is interesting that the amount of missing data was lower in the case group. The possible reasons for this may be that more ICU personnel are involved and actively take responsibility for the prescription of nutrition or that the primary ICU wants to submit documentation in optimal condition. As an incidental finding, this is important because a lack of documentation is associated with poorer quality of care (47). Although the differences were not significant, there were tendencies for 
patients who were transferred to receive less prescribed nutrition. It has previously been shown that it is difficult to achieve the nutritional goals of critically ill patients (48-50). We argue that achieving the goals may be further hampered in connection with transfers, so consideration should be given to compensating for this.

\section{Strengths and limitations}

Studying the incidence of MNC among patients undergoing an interhospital intensive care unitto-unit capacity transfer was complex and challenging. First, we argue that a retrospective matched case-control chart review was an appropriate method to answer the research question. However, retrospective chart reviews have the potential for observer bias and systematic error, especially when there is no access to tested and validated instruments for data collection. To minimise this problem, a data collection tool was designed based on a logical flow for the data collection process. In addition, data collection was performed by only one of the authors. No power calculation was performed. Instead, we included all interhospital intensive care unit-tounit capacity transfers from when the quality indicator 'transfer to another ICU due to lack of resources' was introduced in the two ICUs. Such a strategy can be considered a total survey, which can be considered a strength. We tried to optimise matching through a hierarchy of criteria. Despite this, the matching criterion for total burden of care per hour or day and NEMS per day could not be optimally matched, which may be a limitation that could have affected the results. In the present study, we chose to see the transfer as a process consisting of a transfer preparation, transport and handover procedure. This meant that we performed data collection at both the referring and accepting ICUs. A transfer to an ICU without a lack of resources aims to better maintain a high quality of patient care, which can reduce the risk of MNC. Hence, studying MNC at the accepting ICU can be questioned. We still consider it valuable to study $\mathrm{MNC}$ at both the referring and accepting ICUs because MNC can have different origins. For 
example, at the referring ICU, the focus is on the transfer itself, and at the accepting ICU, information losses and reduced patient overview may delay the start of relevant caring activities. A more optimal approach would have been to simultaneously compare the distribution regarding $\mathrm{MNC}$ between the referring and accepting ICUs. At the same time, we argue that the MNC variables included in the current study are relevant to the care of critically ill patients. One limitation of the present study is that it consisted of a small number of patients and only represented two level 3 ICUs within the same geographical region.

\section{Conclusion}

The present study identified a significantly increased incidence of MNC in the form of missed mobilisation and oral care in patients subjected to interhospital intensive care unit-to-unit capacity transfers. Thus, our findings complement earlier research that has identified increased ICU length of stay and increased mortality as being associated with interhospital intensive care unit-to-unit transfers. Although interhospital capacity transfers will continue to be necessary in the future, the results from the current study contribute to an increased awareness of the risks of MNC during such transfers. Such a contribution is important in our endeavour to make these transfers safer for vulnerable critically ill patients. Future studies focusing on ICU transfers need to consider MNC when the causes of increased ICU length of stay and mortality are investigated. 
Abbreviations

CCRN: Critical care registered nurse

CRNA: Certified registered nurse anaesthetist

EMR: Estimated mortality risk

ICU: Intensive care unit

IPPV: Invasive positive pressure ventilation

Kcal: Kilocalories

MNC: Missed nursing care

NEMS: Nine equivalents of nursing manpower use score

NIPPV: Noninvasive positive pressure ventilation

SAPS: Simplified acute physiology score

SIR: Swedish intensive care registry

VAP: Ventilator-associated pneumonia 


\section{Declarations}

\section{Ethics approval and consent to participate}

This study was approved by the Regional Ethical Review Board in Sweden (Dnr 507-16). Because this was a registry and medical record-based study of an observational nature, individual patient consent was waived by the ethical review board.

\section{Consent for publication}

Not applicable.

\section{Availability of data and materials}

The datasets used and/or analysed during the current study are available from the corresponding author on reasonable request.

\section{Competing interests}

The authors declare that they have no competing interests.

\section{Funding}

This research did not receive any specific grant from funding agencies in the public, commercial or not-for-profit sectors.

\section{Authors' contributions}

All the authors-JK, IF, KS and $\mathrm{MH}$ - have substantially and equally contributed to the manuscript, including the design, analysis, interpretation of data, drafting and editing of the final manuscript. All data collection was conducted by JK. All authors read, reviewed and approved the final manuscript.

\section{Acknowledgements}

We would like to thank the managers and health personnel at the included ICUs for their interest and involvement in the study, as well as for giving us access to the study locations. 


\section{References}

1. Swedish Intensive Care Registry. The Swedish Intensive Care Registry Data Output Portal. 2019. http://portal.icuregswe.org/utdata/home Accessed 5 Dec 2019.

2. Intensive Care Society. Guidance on: The transfer of the critically ill adult. https://www.ficm.ac.uk/sites/default/files/transfer_critically ill adult 2019.pdf (2019). Accessed 16 May 2021.

3. Grier S, Brant G, Gould TH, von Vopelius-Feldt J, Thompson J. Critical care transfer in an English critical care network: analysis of 1124 transfers delivered by an ad-hoc system. J Intensive Care Soc. 2020;21(1):33-39.

4. Barratt H, Harrison DA, Rowan KM, Raine R. Effect of non-clinical inter-hospital critical care unit to unit transfer of critically ill patients: a propensity-matched cohort analysis. Crit Care. 2012;16(5):R179.

5. Duke GJ, Green JV. Outcome of critically ill patients undergoing interhospital transfer. Med J Aust. 2001;174(3):122-5.

6. Droogh JM, Smit M, Absalom AR, Ligtenberg JJ, Zijlstra JG. Transferring the critically ill patient: are we there yet? Critical Care. 2015;19(1):62.

7. Lyphout C, Bergs J, Stockman W, Deschilder K, Duchatelet C, Desruelles D, et al. Patient safety incidents during interhospital transport of patients: a prospective analysis. International Emergency Nursing. 2018;36:22-26.

8. Swickard S, Winkelman C, Hustey FM, Kerr M, Reimer AP. Patient Safety Events during Critical Care Transport. Air Med J. 2018;37(4):253-258.

9. Droogh JM, Smit M, Hut J, de Vos R, Ligtenberg JJ, Zijlstra JG. Inter-hospital transport of critically ill patients: expect surprises. Critical Care. 2012;16(1):R26.

10. Oras J, Strube M, Rylander C. The mortality of critically ill patients was not associated with inter-hospital transfer due to a shortage of ICU beds - a single-centre retrospective analysis. J Intensive Care. 2020;8(1):82.

11. Parenmark F, Walther SM. Intensive care unit to unit capacity transfers are associated with increased mortality. an observational cohort study on patient transfers in the Swedish Intensive Care Register. PREPRINT (Version 1). https://doi.org/10.21203/rs.3.rs-153437/v1 (2021). Accessed 2 Jun 2021.

12. Kiss T, Bolke A, Spieth PM. Interhospital transfer of critically ill patients. Minerva Anestesiol. 2017;83(10):1101-1108.

13. Kalisch BJ, Gosselin K, Choi SH. A comparison of patient care units with high versus low levels of missed nursing care. Health Care Manage Rev. 2012;37(4):320-8.

14. Kalisch BJ, Lee KH. The impact of teamwork on missed nursing care. Nurs Outlook. 2010;58(5):233-41.

15. Dietz AS, Pronovost PJ, Mendez-Tellez PA, Wyskiel R, Marsteller JA, Thompson DA, et al. A systematic review of teamwork in the intensive care unit: what do we know about teamwork, team tasks, and improvement strategies? J Crit Care. 2014;29(6):908-14.

16. Chaboyer W, Harbeck E, Lee BO, Grealish L. Missed nursing care: an overview of reviews. Kaohsiung J Med Sci. 2021;37(2):82-91.

17. Recio-Saucedo A, Dall'Ora C, Maruotti A, Ball J, Briggs J, Meredith P, et al. What impact does nursing care left undone have on patient outcomes? Review of the literature. J Clin Nurs. 2018;27(11-12):2248-2259.

18. Kalisch BJ, Xie B. Errors of Omission: Missed Nursing Care. West J Nurs Res. 2014;36(7):875-90.

19. Ball JE, Bruyneel L, Aiken LH, Sermeus W, Sloane DM, Rafferty AM, et al. Post-operative mortality, missed care and nurse staffing in nine countries: a cross-sectional study. Int J Nurs Stud. 2018;78:10-15.

20. Badawy MAE. Correlates of missed nursing care in medical intensive care units: factors contributing to errors of omission. Cairo University: LAP LAMBERT Academic Publishing; 2014. p. 3-229 
21. von Elm E, Altman DG, Egger M, Pocock SJ, Gøtzsche PC, Vandenbroucke JP.

Strengthening the Reporting of Observational Studies in Epidemiology (STROBE) statement: guidelines for reporting observational studies. BMJ. 2007;335(7624):806-8.

22. Intensive Care Society. Guidelines for the provision of intensive care services. https://www.ficm.ac.uk/sites/default/files/gpics-v2.pdf (2019). Accessed 3 Jun 2021.

23. Marshall JC, Bosco L, Adhikari NK, Connolly B, Diaz JV, Dorman T, et al. What is an intensive care unit? A report of the task force of the World Federation of Societies of Intensive and Critical Care Medicine. J Crit Care. 2017;37:270-276.

24. Swedish Association for Anesthesia and Intensive Care and the Swedish Intensive Care Society - SFAI. Guidelines for Swedish intensive care. https://sfai.se/wpcontent/uploads/2015/02/Riktlinjer-Svensk-Intensivv\%C3\%A5rd_rev-2015.pdf (2015). Accessed 3 Jun 2021.

25. Le Gall JR, Lemeshow S, Saulnier F. A new Simplified Acute Physiology Score (SAPS II) based on a European/North American multicenter study. JAMA. 1993;270(24):2957-63.

26. Moreno RP, Metnitz PG, Almeida E, Jordan B, Bauer P, Campos RA, et al. SAPS 3-from evaluation of the patient to evaluation of the intensive care unit. Part 2: development of a prognostic model for hospital mortality at ICU admission. Intensive Care Med. 2005;31(10):1345-55.

27. Reis Miranda D, Moreno R, Iapichino G. Nine equivalents of nursing manpower use score (NEMS). Intensive Care Med. 1997;23(7):760-5.

28. Perren A, Previsdomini M, Perren I, Merlani P. High accuracy of the nine equivalents of nursing manpower use score assessed by critical care nurses. Swiss Med Wkly. 2012;142:w13555.

29. Zhang L, Hu W, Cai Z, Liu J, Wu J, Deng Y, et al. Early mobilization of critically ill patients in the intensive care unit: A systematic review and meta-analysis. PLoS One. 2019;14(10):e0223185.

30. Singer P, Blaser AR, Berger MM, Alhazzani W, Calder PC, Casaer MP, et al. ESPEN guideline on clinical nutrition in the intensive care unit. Clin Nutr. 2019;38(1):48-79.

31. McClave SA, Taylor BE, Martindale RG, Warren MM, Johnson DR, Braunschweig C, et al. Guidelines for the Provision and Assessment of Nutrition Support Therapy in the Adult Critically Ill Patient: Society of Critical Care Medicine (SCCM) and American Society for Parenteral and Enteral Nutrition (A.S.P.E.N.). JPEN J Parenter Enteral Nutr. 2016;40(2):159211.

32. Zhao T, Wu X, Zhang Q, Li C, Worthington HV, Hua F. Oral hygiene care for critically ill patients to prevent ventilator-associated pneumonia. Cochrane Database Syst Rev. 2020;12(12):CD008367.

33. Kaji AH, Schriger D, Green S. Looking through the retrospectoscope: reducing bias in emergency medicine chart review studies. Ann Emerg Med. 2014;64(3):292-8.

34. Gregory KE, Radovinsky L. Research strategies that result in optimal data collection from the patient medical record. Appl Nurs Res. 2012;25(2):108-16.

35. Martin WE, Bridgmon KD. Quantitative and Statistical Research Methods: From Hypothesis to Results. Hoboken: Wiley; 2012.

36. Nordstokke D, Zumbo B, Cairns SL, Saklofske D. The operating characteristics of the nonparametric Levene test for equal variances with assessment and evaluation data. Practical Assessment, Research \& Evaluation. 2011;16:1-8.

37. Nordstokke DW, Zumbo BD. A new nonparametric Levene test for equal variances. Psicológica. 2010;31(2):401-430.

38. Rhodes A, Ferdinande P, Flaatten H, Guidet B, Metnitz PG, Moreno RP. The variability of critical care bed numbers in Europe. Intensive Care Med. 2012;38(10):1647-1653.

39. Bauer J, Brüggmann D, Klingelhöfer D, Maier W, Schwettmann L, Weiss DJ, et al. Access to intensive care in 14 European countries: a spatial analysis of intensive care need and capacity in the light of COVID-19. Intensive Care Med. 2020;46(11):2026-2034.

40. Okada Y, Unoki T, Matsuishi Y, Egawa Y, Hayashida K, Inoue S. Early versus delayed mobilization for in-hospital mortality and health-related quality of life among critically ill patients: a systematic review and meta-analysis. J Intensive Care. 2019;7(1):57. 
41. Tipping CJ, Harrold M, Holland A, Romero L, Nisbet T, Hodgson CL. The effects of active mobilisation and rehabilitation in ICU on mortality and function: a systematic review. Intensive Care Med. 2017;43(2):171-183.

42. Zang K, Chen B, Wang M, Chen D, Hui L, Guo S, et al. The effect of early mobilization in critically ill patients: a meta-analysis. Nurs Crit Care. 2020;25(6):360-367.

43. Dong Z, Liu Y, Gai Y, Meng P, Lin H, Zhao Y, et al. Early rehabilitation relieves diaphragm dysfunction induced by prolonged mechanical ventilation: a randomised control study. BMC Pulm Med. 2021;21(1):106.

44. Doiron KA, Hoffmann TC, Beller EM. Early intervention (mobilization or active exercise) for critically ill adults in the intensive care unit. Cochrane Database of Systematic Reviews. 2018(3).

45. Labeau SO, Conoscenti E, Blot SI. Less daily oral hygiene is more in the ICU: not sure. Intensive Care Med. 2021;47(3):334-336.

46. Reissmann DR, John MT, Schierz O, Kriston L, Hinz A. Association between perceived oral and general health. J Dent. 2013;41(7):581-9.

47. Zegers M, de Bruijne MC, Spreeuwenberg P, Wagner C, Groenewegen PP, van der Wal G. Quality of patient record keeping: an indicator of the quality of care? BMJ Qual Saf. 2011;20(4):314.

48. Cahill NE, Dhaliwal R, Day AG, Jiang X, Heyland DK. Nutrition therapy in the critical care setting: What is "best achievable" practice? An international multicenter observational study. Crit Care Med. 2010;38(2):395-401.

49. Ridley EJ, Peake SL, Jarvis M, Deane AM, Lange K, Davies AR, et al. Nutrition therapy in Australia and New Zealand intensive care units: an International Comparison Study. JPEN J Parenter Enteral Nutr. 2018;42(8):1349-1357.

50. Heyland DK, Dhaliwal R, Wang M, Day AG. The prevalence of iatrogenic underfeeding in the nutritionally 'at-risk' critically ill patient: results of an international, multicenter, prospective study. Clin Nutr. 2015;34(4):659-66. 


\section{Additional file 1. Data collection tool.}

\section{1.}

All patients were coded with numbers from 1-189

\section{2.}

Identify the chart review time period (a total of 30 hours) for the case patient based on the time (nearest full hour) when the patient left the primary ICU and 15 hours back in time and the time (nearest full hour) when the patient arrived at the secondary ICU and 15 hours forwards in time.

\section{3.}

Document the primary ICU's total care burden during the day for the case patient's identified chart review time period.

\section{4.}

Identify the chart review time period (a total of 30 hours) for the matched control patient based on the same time period as the case patient and based on the day with the most equivalent total care burden for the ward.

\section{5.}

Identify and document the patient's highest form of ventilation during the chart review time period (1. Spontaneous, 2. High-flow oxygen therapy, 3. CPAP, 4. NIPPV and 5. IPPV).

\section{6.}

Review and document whether the case patient has been prescribed nutrition at the primary- and/or secondary $\mathrm{ICU}(\mathrm{Yes}=1, \mathrm{No}=0)$, and then document the amount of prescribed kcal. Finally, review and document the amount of kcal obtained for the case patient.

\section{7.}

Review whether the control patient has been prescribed nutrition $(\mathrm{Yes}=1, \mathrm{No}=2)$ and then document the amount of prescribed kcal. Finally, review and calculate the amount of kcal obtained for the control patient.

\section{8.}

Review and document the number of mobilisations for the case patient at the primary- and secondary ICU and sum these up to a total number of mobilisations.

\section{9.}

Review and document the total number of mobilisations for the control patient.

10.

Determine the total number of possible tooth brushings for the case and control patients, based on the time period for the chart review.

\section{1.}

Review and document the number of tooth brushings for the case patient at the primary and secondary ICU and sum these up to a total number of tooth brushings.

\section{2.}

Review and document the total number of tooth brushings for the control patient.

13.

Review and document the number of accomplished oral care for the case patient at the primary and secondary ICU and sum these up to a total number of accomplished oral care.

14.

Review and document the total number of accomplished oral care for the control patient. 
Additional file 1. Data collection tool.

\begin{tabular}{|c|c|c|c|c|c|c|c|c|c|c|c|}
\hline $\begin{array}{l}\text { Uniquely coded } \\
\text { ID }\end{array}$ & $\begin{array}{l}\text { Chart review } \\
\text { time period }\end{array}$ & \multicolumn{2}{|c|}{$\begin{array}{l}\text { Total burden of } \\
\text { care for primary } \\
\text { ICU }\end{array}$} & \multicolumn{2}{|c|}{$\begin{array}{l}\text { Type of } \\
\text { ventilation }\end{array}$} & & & & & & \\
\hline \multicolumn{12}{|l|}{ Case patient } \\
\hline \multicolumn{12}{|l|}{ Control patient } \\
\hline \multicolumn{12}{|l|}{ Control patient } \\
\hline $\begin{array}{l}\text { Case patient, } \\
\text { kcal } \\
\text { prescribed } \\
\text { primary ICU }\end{array}$ & $\begin{array}{l}\text { Case patient, } \\
\text { kcal } \\
\text { prescribed } \\
\text { secondary } \\
\text { ICU }\end{array}$ & $\begin{array}{l}\text { Case patient, } \\
\text { amount kcal } \\
\text { prescribed }\end{array}$ & $\begin{array}{l}\text { Cas } \\
\mathrm{kcal}\end{array}$ & $\begin{array}{l}\text { patient } \\
\text { bbtained }\end{array}$ & $\begin{array}{l}\text { Control } \\
\text { patient, kcal } \\
\text { prescribed }\end{array}$ & $\begin{array}{l}\text { Control } \\
\text { patient } \\
\text { amount kcal } \\
\text { prescribed }\end{array}$ & $\begin{array}{l}\text { Control } \\
\text { patient kcal } \\
\text { obtained }\end{array}$ & $\begin{array}{l}\text { Case patient, } \\
\text { number of } \\
\text { mobilisations } \\
\text { primary ICU }\end{array}$ & $\begin{array}{l}\text { Case patient, } \\
\text { number of } \\
\text { mobilisations } \\
\text { secondary } \\
\text { ICU }\end{array}$ & $\begin{array}{l}\text { Case patient, } \\
\text { total number } \\
\text { of } \\
\text { mobilisations }\end{array}$ & $\begin{array}{l}\text { Control } \\
\text { patient, total } \\
\text { number of } \\
\text { mobilisations }\end{array}$ \\
\hline & & & & & & & & & & & \\
\hline & & & & & & & & & & & \\
\hline & & & & & & & & & & & \\
\hline
\end{tabular}

\begin{tabular}{|l|l|l|l|l|l|l|l|}
\hline $\begin{array}{l}\text { Case and control } \\
\text { patient, number of } \\
\text { possible tooth } \\
\text { brushings }\end{array}$ & $\begin{array}{l}\text { Case patient, } \\
\text { number of tooth } \\
\text { brushings primary } \\
\text { ICU }\end{array}$ & $\begin{array}{l}\text { Case patient, } \\
\text { number of tooth } \\
\text { brushings } \\
\text { secondary ICU }\end{array}$ & $\begin{array}{l}\text { Case patient, total } \\
\text { number of tooth } \\
\text { brushings }\end{array}$ & $\begin{array}{l}\text { Control patient, } \\
\text { total number of } \\
\text { tooth brushings }\end{array}$ & $\begin{array}{l}\text { Case patient, } \\
\text { number of } \\
\text { accomplished oral } \\
\text { care primary ICU }\end{array}$ & $\begin{array}{l}\text { Case patient, } \\
\text { number of } \\
\text { accomplished oral } \\
\text { care secondary } \\
\text { ICU }\end{array}$ & $\begin{array}{l}\text { Case patient total } \\
\text { number of } \\
\text { accomplished oral } \\
\text { care }\end{array}$ \\
\hline & & & $\begin{array}{l}\text { Control patient } \\
\text { total number of } \\
\text { accomplished oral } \\
\text { care }\end{array}$ \\
\hline & & & & & & & \\
\hline & & & & & & \\
\hline
\end{tabular}

